\title{
A Roundtable of American Studies Journals
}

\section{Hélène Quanquin and Cécile Roudeau}

\section{(2) OpenEdition}

\section{Journals}

\section{Electronic version}

URL: https://journals.openedition.org/transatlantica/17445

DOI: 10.4000/transatlantica. 17445

ISSN: $1765-2766$

\section{Publisher}

Association française d'Etudes Américaines (AFEA)

\section{Electronic reference}

Hélène Quanquin and Cécile Roudeau, "A Roundtable of American Studies Journals", Transatlantica [Online], Hors-série | 2021, Online since 01 October 2021, connection on 11 October 2021. URL: http:// journals.openedition.org/transatlantica/17445 ; DOI: https://doi.org/10.4000/transatlantica.17445

This text was automatically generated on 11 October 2021

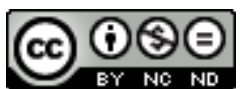

Transatlantica - Revue d'études américaines est mise à disposition selon les termes de la licence Creative Commons Attribution - Pas d'Utilisation Commerciale - Pas de Modification 4.0 International. 


\title{
A Roundtable of American Studies Journals
}

\author{
Hélène Quanquin and Cécile Roudeau
}

\section{Introduction}

In this contribution, Transatlantica has invited the editors of a variety of American Studies journals in Britain, France, and the United States to reflect together on issues of academic publication, e-journal and print edition, as well as the contours of the field of American Studies, and the societal implications of publishing an academic journal, at a time of debates on the decolonization of academic research and curriculum. The following text is a collaborative and collective contribution resulting from this conversation. The participants are: Elizabeth Duquette, Professor of English at Gettysburg College and Editor in chief of J19: The Journal of Nineteenth-Century Americanists; Nathan Grant, Associate Professor of English at Saint Louis University and Editor in chief of African American Review; Michael Jonik, Senior Lecturer in English and American Literature at the University of Sussex and Reviews and Special Issues Editor of Textual Practice; John Wills, Reader in American History and Culture at the University of Kent and Editor in chief of the European Journal of American Culture; and the nine editors of RITA: Interdisciplinary Journal of Papers on the Americas.

TRANSATLANTICA: What is your perspective, as editors, on the evolution of the field of American Studies in your respective countries? What new directions do you see as important in the field?

Nathan Grant (African American Review): I feel that the field is moving faster than we are. The sociopolitical events of the last year or so-the pandemic; the presidential elections, the continuing political chicanery surrounding these, and the threat to democracy (as we understand it), the killings of George Floyd, Breonna Taylor, and others and the international consciousness they provoked-have combined with attacks on academic freedom to create an unmistakable tilting toward rightist, even fascist behaviors and policies. Gauging the proper response to these tendencies seems to be top of mind right now among those of us on the left in the US, and many scholars appear to be trying to adapt their perceptions of their disciplines 
to these events which, even for scholars of my generation, have never achieved the felt urgency that they appear to have manifested since 2016.

It does appear that overall, new perspectives, new counterstatements to older notions about American history, education, race, and the drive to preserve an academic freedom that generates these discussions are being reassessed. Through cultural studies and American Studies, new ideas in law, sociology, medicine (particularly public health), history, criminal justice, and the environment, to name a few, seem right now to be driving conversations among most US intellectuals.

RITA: RITA was created in 2008 by students of the French Institute of Latin American Studies (Institut des Hautes Études de l'Amérique Latine, IHEAL). However, far from focusing only on Latin American issues, the first editorial members understood the need to address issues pertaining to all of the Americas. Ever since, RITA has valued this approach and made an effort-even though it can be a challenge-to select themes that offer the possibility to analyze issues happening in South, Latin, and North America. RITA is one of the only academic journals in France to do so.

In the field of American Studies, topics such as identity issues, inequalities, and forms of violence have been addressed in the past and continue to be studied. However, new directions are gaining momentum such as gender studies and environmental studies. RITA has addressed them in issues on "Women in the Americas" and on "Global changes in the Americas."

John Wills (European Journal of American Culture): In the United Kingdom, while the market for American Studies as an undergraduate degree has diminished over recent years, the discipline continues to be a rich and dynamic area of postgraduate research and established scholarly involvement. The British Association for American Studies (BAAS) remains a crucial institution in the promotion of the discipline, while the British-based Journal of American Studies has increased its issue number per year, and continues to provide a vibrant array of pieces. Some recent trends include a new and very welcome push on research and teaching that tackles today's climate crisis (evidenced in the Greener BAAS initiative), border, migration and transatlantic foci, health and disability studies, food studies, musicology and performance studies, more LBGTQ+ work and representation, and research around the concept of Digital America, allied to the development of historical game studies. Work linked with racial justice and Black Lives Matter is also growing and very welcome. Finally, there has been a greater internationalization of the discipline, aided by contemporary Zoom culture and online conferences.

Michael Jonik (Textual Practice): American Studies in the UK has substantially evolved in the past decade or so. With the formation of important new networks such as BrANCA (The British Association of Nineteenth-Century Americanists) and the increased prominence of the BAAS (British Association of American Studies), we have been fortunate to gain a larger institutional foothold and to have experienced a broadening interest especially in research into the pre-1900 period from exciting historical, political, and philosophical perspectives. While Textual Practice publishes literary criticism from across the periods, we have been pleased to publish important American-literature-focused special issues in the past few years on "American Literature and the Philosophical," "Muriel Rukeyser's The Life of Poetry," "Pynchonomics," or the upcoming "Rescaling Melville." We regularly publish articles 
on writers from Hawthorne or Dickinson to Loy, Stevens, Morrison, Lerner, or DeLillo, to name just a few.

Elizabeth Duquette (J19): Perhaps the most important new direction we've identified is a reevaluation of historicism-what counts as context, how we navigate the relationship between a past that is both familiar and strange, and a present that is likewise familiar and strange-and the ways this might alter what counts as context or as evidence. Indeed, recently we published what we called a "mega-forum" on the topic of "Biography and Evidence," built from essays we'd received as well as those we solicited. Some scholars embraced various versions of presentism, arguing for the value of drawing connections between the past and present, while others urged caution, stressing the ways that a presentist approach erased the past in all its weirdness and contingency. That this is part of the reevaluation of context, which may or may not "stink," as Rita Felski put it, is certainly true. ${ }^{1}$

John Wills (European Journal of American Culture): From this first section, the issue of "speaking to the now" seems such a crucial thing, yes, there are challenges of presentism and perspective, but all of us seem committed to our journals having something to "say."

TRANSATLANTICA: In your view, what are the academic, societal, and political implications of publishing an academic journal as well as the editorial choices made by the journals themselves? Are academic journals gatekeepers, shape-shifters?

Elizabeth Duquette (J19): At J19 we think of ourselves as facilitators rather than gatekeepers, although we are keenly aware that we exert influence on the field no matter what we think. Still, to try to make sure this is no mere flattering self-image, we are attentive to the ways the journal can boost careers and profiles, and thus pay particular attention to the submissions from early-career scholars, particularly those who have been historically underrepresented in our field.

At the same time, we see editing as a process, one with lots of gray areas. We approach each submission with care, looking for ways to help the author succeed. Sometimes this might mean suggesting an author take another pass through an essay before we send it out for review, sometimes it means working with an author after review to guarantee the essay's success. In every instance, we try to identify readers who are generous but fair, thoughtful but rigorous.

Because the journal is related to an academic society, $\mathrm{C} 19$, we have an obligation to keep the interests of the society's members in mind. At the same time, however, we are always eager to expand the field's parameters and help our members encounter ideas, methodologies, or texts important to other disciplines, like, for example, religion or political theory.

Michael Jonik (Textual Practice): It could well be that we are the Benedictines of our time, laboring away in relative solitude as the digital Dark Age rages around us. More seriously, the political and societal implications of academic publishing can be slow and take time, but they are central to shaping intellectual discourses that go beyond the academy. Journals are perhaps less gated communities than play areas or laboratories for new ideas to be tested out. 
John Wills (European Journal of American Culture): The journal I edit has a forty-year history and there is a responsibility to retain its scholarly reputation. It has a clear mandate to explore the cultural dimensions of the American experience, and in its own way, highlights the importance of culture (alongside politics, economics, demographics, and other forces) in shaping the American condition. Sometimes the cultural lens leads to more controversial and contemporary-framed pieces (for example, we've published on Trump, Black Lives Matter, and police brutality) and sometimes those pieces have specific social or political messages. However, dual blind peer review and careful editorial oversight, in my opinion, assure the pieces have validity in speaking to the specifics of today.

I think there's a neutrality to being facilitator that sometimes I move beyond (good or bad!), to encourage certain special issues or push a topic to be looked at. I adore the idea of "play areas or laboratories"-although sometimes the traditional format of journals, allied with extensive peer review, can reduce the "playfulness"-and we should maybe be more aware of that potential.

RITA: Information overload in our era is a fact. Everything goes quickly. As an academic journal, we try to grasp this reality and choose issues that disrupt the Americas in our present time (e.g., articles on populism, the transformation of the cities, global changes, etc.). What is challenging is that as an academic journal, even though there is excess of information, we need to take the time to analyze what is going on in the world to problematize it, broaden our knowledge, and understand our societies. We want to make sure to separate the wheat from the chaff. Our purpose is to put current American issues into perspective and not be subdued by the immediacy of our modern societies. In that sense we can argue that RITA is a gatekeeper.

However, RITA is also a shape-shifter for two main reasons. First, the analyses and debates raised by the articles contribute to shaping the understanding of our societies. Second, RITA is an academic journal run by young researchers that publishes articles written by young researchers. In France, it is not easy for a young scholar to be published in a renowned journal. Yet, it is expected to be recognized in the academic world. Thus, we value the articles sent by young researchers: we accompany them throughout the process of publication, we act as intermediaries between them and the experienced researchers who peer review their articles, we familiarize them with scientific standards, and we put emphasis on this as a learning experience. This way, we try to avoid being gatekeepers while still being scientifically rigorous.

Nathan Grant (African American Review): As often as is possible, I want to put out a journal with a provocative voice, one that gives its audience much to think and talk about. In so many instances, however, there can be real limitations as regards discipline-African American Review is principally a literary and artistic endeavor, and even though there's much to say about the issues I mentioned in answering Question 1 under that rubric, the tests of those ideas are academic ones. That is, there's far less room for experiment and speculation-or, shall I say that the existence of both in the academic journal is ultimately attenuated by the demands of an academic audiencethan one might find in nonacademic contemporary cultural journalism (e.g., The Atlantic, The New Yorker, etc.). There's fact-checking in both, but the fact of peer 
review and the attendant responsibility to reveal detailed source material-in short, to endure vetting by different journalistic standards is to create a discernibly different publication. And so, all journals are gatekeepers, necessarily so-and that shouldn't be a dirty word. In every editorial decision, regardless of the nature of the publication, the editor is managing the tension between being both conversationally relevant and constitutively distinctive. And in academe, we as editors also have an unstated responsibility to keep conversations going in spite of peer review that may from time to time be unfavorable. If, in asking whether editors through their journals are gatekeepers you mean that unwelcome (or even effusive) talk about someone's ideas should be limited to the purely social sphere, then that's in the job description, too. I can just imagine that if there were no such thing as double-blind peer review, academia's written values would grind to a screeching halt.

Do we "shape" the profession? (I think that's partly what you mean by "shapeshifter.") Yes and no. I have a vision for AAR that, as I hope I've suggested above, can be nimble enough to be managed against a changing academic and disciplinary landscape. But even though I like to think I'm mastering all of the levers all of the time; I don't always get it right. And sometimes when I got it right, I was lucky. Or it was because an author was amenable to negotiation. Or I was just savvy enough, just careful enough in a questionable case to avoid having what is every editor's nightmare: the Alan Sokal moment. ${ }^{2}$

Elizabeth Duquette (J19): Nathan's comment makes me think about the changing relationship(s) between scholarship and activism. Obviously, that's a topic that is more expansive than a comment could begin to address-but, as an editor, it does make me think about access and audience, and how journals might best support this kind of work.

Nathan Grant (African American Review): Elizabeth, I have often wondered how J19 so successfully navigates these waters, perhaps particularly without reaching into C21. AAR tries to push the boundaries of literary criticism by including essays on cultural studies, visual art, and film, and we also try to ignite thinking about these with our cover art. Our presence on social media is also becoming more robust all the time, but I'm never confident that I can see what the end result will be. I'm also fortunate to be an associate editor of the A-Line / a journal of progressive thought (Hortense J. Spillers and Rich Blint, editors), a journal that allows (and seeks!) a bit more edginess, but right now this fledgling journal with a small but smart following is really still seeking its voice. I suppose that with limited budgets and increasing time constraints being levied against editors (and authors) everywhere, it's harder to be timely without losing both focus and continuity, which would seem to be indispensable to print-progressivism, or any other form of progressivism.

I guess I also wonder from others whether we as editors really miss, or otherwise lose control of some of the more trenchant issues of our time because we're blinded by the economic realities of the academic marketplace. We seem to want to discuss them in focused ways, but we do encounter these realities as well as other obstacles. Are there also differences in our approaches to these discussions because of specific political pressures in the US and Europe? Or am I widening the lens too much? 
TRANSATLANTICA: To what extent have your journal policies and/or your editorial choices taken into account current debates on the decolonization of academic research and curriculum?

Michael Jonik (Textual Practice): We take decolonization very seriously in terms of both editorial choices and insofar as the journal participates in curricular choices. We hope to provide a resource for literary scholars to both understand what decolonization can mean for our critical reading of literature, and to measure its effects in a variety of institutional and international cultural contexts. Very recently we published what I think is an important "Turning Point" by Priyamvada Gopal called "On Decolonisation and the University," which I urge you to read.

John Wills (European Journal of American Culture): We currently welcome and promote the decolonization process, and our sympathies are reflected in both our management staffing and journal content. We endeavor to incorporate a greater diversity of voices. Future guest-edited issues include a Contemporary Indigenous Culture special as well as a Black Lives Matter special. However, moving forward, an official statement or clearer outline of action may be advantageous.

Nathan Grant (African American Review): In the case of US literary and cultural journals, the current debates surrounding the teaching of "correct" or "patriotic" version of US history has yet to quite materialize-these debates are taking place mostly on civic and pre-university levels, and they are certain to have their impact on university teaching and curricula in years, or perhaps just months to come. I don't believe we're there yet-or rather, we perhaps are there, but in different ways. We've had recurring interoffice discussions about, e.g., the ultimate value of teaching BIPOC/LGBTQ+ works as a means of making the meaning of American culture more broadly relatable, or about BIPOC/LGBTQ+ literature as insurrectionist literature-but that conversation vies for prominence with, say, the current and unnecessarily noisy debates regarding critical race theory, which itself has taken its turn after the Nikole Hannah-Jones/University of North Carolina affair. ${ }^{3}$ These are all relatively recent developments or resurfacings, having gained their currently discernible impetus in only the last five years or so, I would say, but if this is what the question asks, we will continue to publish those very articles that focus on these issues.

RITA: RITA has been taking into account these debates since its first issues in the 2010s, with for example an issue on identities, the Africas of the Americas, indigenous cultures, and women in the Americas. Every year, we also interview different types of actors (academics, activists, artists, etc.). In 2013, RITA published an interview with Aimé Césaire, in which he explained how issues of colonization and race in Martinique nourished the rebellion that is constitutive of his poetry. In our next issue in September 2021, decolonization of the minds and artistic statements of social minorities will be discussed through various articles analyzing the literatures produced in the suburbs in the Americas.

Also, the fact that RITA publishes interdisciplinary papers allows us to take into account and exchange views on these issues through historical, geographical, anthropological, sociological, literary, and artistic perspectives.

Elizabeth Duquette (J19): We belong to an organization, the Council of Editors of Learned Journals, and read with interest the debates on the list-serv about how to reorient journals to these newer areas of interest. At the same time, though, this has 
not been an area of particular challenge for J19. People who submit to our journal tend to be attuned to these concerns. This should not be read as complaisance, however. We remain committed to making J19 a welcoming place for scholars of color to submit their work and to helping our field, which has remained predominantly white even as the texts we consider have come to include works by Black, Indigenous, Latinx, or Asian-American writers, increase its necessary reconfiguration.

tRANSATLANTica: Peer-reviewing policies have recently been under attack. Have you implemented practices in order to mitigate their bias?

John Wills (European Journal of American Culture): On peer reviewing, we always seek to locate two specialist academics who provide supportive, anonymous reports. I think that a minimum of two goes some way to mitigate any underlying biases, and our reviewers have done excellent jobs in the past in providing feedback. We actively encourage authors to positively revise pieces, rather than start over. I'm keen to avoid peer reviewing that is ego-based or destructive for the author.

Elizabeth Duquette (J19): Each essay we review must be read by a member of the editorial board, so we are careful to appoint board members with a diverse array of perspectives and identities. Essays are also read by field specialists who aren't on the board, which means we can always find some balance between views. Like most editors, we have a great deal of latitude: if a report comes back and seems biased, we can always solicit another or weigh that reader's comments less in our evaluation. We never send unedited comments to authors.

This is an instance in which being on an editorial team is especially useful, even if we are both white women; ${ }^{4}$ we are able to keep one another accountable. We take great pride in the fact that even authors we reject thank us for the reports we've solicited about their scholarship.

Nathan Grant (African American Review): Again, I think I'd need more specificity here. There are all kinds of biases in peer reviewing, to be sure, but they don't stand apart from certain assumptions also made by authors (that sounds like a bias in itself, doesn't it?).

But if you mean to suggest, e.g., bias in hypothesis testing, in data mining, and the extent to which it can affect the views of potential peer reviewers, I can't say I've seen that-that discussion seems to be dominated in the US mostly by racial disparities in healthcare research, and thus practice, as we have known them. If you mean, however, to inquire more narrowly about the current discussions in peer review and publication, e.g., in race and medieval studies, I don't see that either, since we have yet to receive an essay (since my tenure at AAR began) that discusses that topic in any light. I think the fact that we foreground the premise for our scholarship with sensitivity to race and ethnicity means that we attract very differently focused scholarship and peer review. If you mean simply the fact of double-blind peer review, long the gold standard in our profession, I'd defend that for reasons I've stated above about gatekeeping, and I'll be more explicit about that here: The distrust in scholarship that would ensue if negative or even disrespectful reviewers' identities were known to the reviewed and vice versa would strike a catastrophic blow to Humanities scholarship as the health of disinterested inquiry would be replaced by little more than wounded self-interest. Proof of this likely 
requires no further a look than at the history of book reviewing, both academic and mass-market. But regardless of what's being reviewed, we haven't had difficulty of this sort in my journal because we don't allow anyone whose work is not informed at the doctoral level to review the works of the long-professionalized, which curiously remains a practice in other areas of Humanities scholarship. (We do, however, subject graduate students' scholarly essays to professional peer review, and it never fails to surprise me that I've had to defend this as a means of true professionalization.) I've actually witnessed the destruction of early careers through journals that have allowed this practice, and it's not difficult also to see that its long-term effects, both to vulnerable reviewers and to the profession at large, can be devastating.

Michael Jonik (Textual Practice): We have always followed a double-blind peer reviewing policy and submissions are typically reviewed by two referees. We draw on a wide and diverse set of readers from across the world. To see work from many different perspectives is essential not only to fairness, but also to academic and intellectual rigor.

RITA: To be in line with the current publication rules, the articles of our thematic section are subjected to double-blind peer review. But when the reviewers give conflicting assessments of an article, we (the editorial board members) step in and arbitrate, as we think that our role is to be an intermediary between the authors and the reviewers. We insist on accompanying our-mostly-young authors to help them meet the standards of a scientific paper. In order to achieve this, the nine of us work rigorously and meet regularly to make collective decisions and publish articles that contribute to the understanding of our societies.

We totally agree with John Wills and Elizabeth Duquette. If a reviewer makes harsh statements towards an article/author, we rephrase the statements so that they will be constructive for the author. We are very careful about that, especially since some of our authors are young scholars who publish for the first time. It is important that they feel confident to revise their articles.

Michael Jonik's statement makes us reflect on an important aspect of peer reviewing. We also draw on a wide set of reviewers (especially since the articles can be submitted in 4 languages), but we would like to point out that it becomes more and more difficult to find reviewers, mostly because they are academics whose schedule is very busy.

Elizabeth Duquette (J19): I have a general question about peer reviewing for everyone: we have recently found a tendency for readers to accept everything, even if the reports they've written are justly critical (and most especially if they, or their particular subfield, is referenced in the essay). Some of this seems perhaps to be pandemic-related, some driven by metrics (citations count) -is this something others have experienced and, if yes, any suggestions?

John Wills (European Journal of American Culture): I haven't personally come across this at EJAC, but in those cases we might approach said reader for greater clarity, or perhaps seek an additional reader to reach a firmer conclusion on the merits of the piece. That said, I think there should be sympathetic acknowledgment of the challenges of writing and researching during a global pandemic, and our journal is eager to offer positive support and advice for publishing in today's environment. 
Nathan Grant (African American Review): It does happen from time to time, but despite our willingness to ride out the pandemic with everyone else, it's a delicate balance nonetheless. We tend to be skeptical about reviews that are too favorable if the reviewer's name or work is mentioned, and so we try to spend more time with reviews and drafts to see whether the lily is in fact getting a double-gilding. But then it can be difficult to find additional readers given the time constraints that authors may have, say, for promotion and tenure. If it happens often enough, there's an obvious risk to the journal's reputation as well. But these are just the ordinary hazards, I suppose. We try, as John does at his journal, to get a third reader for a decision, and we inform the author that this is the process that's taking place. In an urgent case, we invite the author to determine whether they'd like to remain with us, or withdraw the piece with our best wishes and resubmit to another journal if they believe that they can get a faster turnaround. I've often offered to write an email (or letter, if for a candidate's file) that conditions are such that peer review is delayed, that we believe in the work, and that a just conclusion can and will be reached in due course. Given the foreshortening of times to review/tenure decisions and given also the additional weight of duty placed upon academics by their departments and divisions, however, that tack unfortunately seems to have less appeal to governing bodies than in even the recent past. And so I'll take this opportunity to warn authors as I do on all the editing panels I'm on-that the notion that journals can turn an essay around in no more than three months is today mostly a myth. Authors should allow at least half as much more time for your essay to evolve through peer review, as reviewers, authors, editors, researchers-all of us-are busier today than we ever were, and I daresay ever wanted to be.

TRANSATLANTICA: What is the place of e-publishing in your respective countries' academic systems and traditions? How do you consider the advantages and limits of the two formats (e-journal vs print) and access policies?

RITA: In France, e-publishing has gained momentum in the past few years and has almost overshadowed print journals. We feel that there is less flexibility when a journal is printed. Indeed, printing a journal means having a budget constraint (and hence, publishing constraints) that impacts the price of the journal and thus can reduce the number of readers who can afford to buy the journal.

The price is not only a problem limited to print journals. Some online journals are also very pricey. The price that they impose is completely at odds with the fact that most research in the social sciences and humanities is carried out with public funds. Universities have to pay for accessing research that they have funded in the first place. Furthermore, many institutions and researchers don't have the budget to subscribe to some of these websites, and as such they are blocked from access.

At RITA, it is our choice to be an online journal, so that our articles can be accessed free of charge. This is something that we value since we think that access to knowledge should be available to everyone. Moreover, being an online journal means having more flexibility in the creation of scientific contents. It is also particularly interesting for the readers and the visibility of articles, since people seldom read a whole issue of an academic journal. 
As a journal with a very small budget, we do not have a print version. However, we are curious about journals that have both online and print editions: do readers have to pay a subscription to get both the online and printed journal? Do you know if you have more online readers than readers who get the print version? Is it the readers (do they tell you so?) who need a print version and/or is it your journal that wants a print version?

John Wills (European Journal of American Culture): I'm personally a fan of journals printing in both formats (our publisher, Intellect, fortunately does this for the European Journal of American Culture). While increasingly the digital format allows greater access, and university libraries actively support it (especially given the COVID situation) there is, in my opinion, an argument for preserving paper culture, and especially in libraries and in the home, it offers a rich analogue experience.

Nathan Grant (African American Review): African American Review is available both on JSTOR and Project MUSE, as well as in print, by subscription. We're pleased that anyone who has access to a university library can have access to us. It's hard for me to say whether the advertising revenue that we have in our print version would be enhanced if it were also to appear on our online version, simply because advertisers would likely balk at paying more for wider distribution to a comparatively small audience. Municipal libraries would probably not seek the databases common to Humanities scholarship that most of its patrons would likely not use. But that said, we appreciate those university libraries that also serve the general public because that means that mostly everyone potentially has access.

As I mentioned, I'm also an associate editor of the relatively new, entirely online journal A-Line, and we're beginning to discuss the directions that fundraising may take as well as talking about going to print with a few choice issues as an experiment. What we do like thus far, though, is that we've created a caring community of editors and authors through both our lack of affiliation with larger platforms, and that editors and makers of art are also contributors, thus making us subject to many of the same rules we set for others. Access is without charge. We're working with the freedom these measures give us now, while remaining aware that that freedom is not necessarily a sustainable practice in either the academic or larger marketplace.

Michael Jonik (Textual Practice): E-Publishing and Open Access journals have become widespread in the UK. For Textual Practice, we publish both online (first) and then in print. This has allowed us the best of both worlds as far as format is concerned.

Elizabeth Duquette (J19): E-publishing is an increasing part of the American academic system, for good and ill. It reduces production costs, although perhaps not subscription fees, and mitigates the climate effects of creating and shipping print journals. That many copies of journals end up in recycling bins is certainly true. Too often, though, we forget that the environmental effects of e-publishing are not neutral for electronic materials must be housed somewhere, in data farms which require power to maintain and cool.

It's also likely that e-published materials will exacerbate a dynamic that is already hurting academic publishing in the United States. In order to decrease the cost of their own collections and to expand the materials they can offer to faculty and 
students, universities and colleges have joined into regional collectives. If your home institution does not have a book, you can easily order it from a nearby library. This exchange has made it much easier to engage in research from schools that don't have a full research collection. At the same time, however, it has also meant that libraries can purchase fewer books-and they are doing precisely this. They can decide to focus on one particular area, knowing that a peer institution nearby will augment their holdings in other fields. These are reasonable choices, but they mean that presses are feeling a financial pinch, one they pass on to authors, especially first-time authors, in the forms of subventions. It is becoming more and more common to find reputable presses asking for authors to pay for the publication of their monographs. That this practice falls hardest on scholars from historically underrepresented groups and on institutions that are not well-funded is obvious.

Still, J19 now offers subscribers the option to opt out of the printed journal and, as much as I lament the change, the reduction in cost is important to me. The days when someone might sit down and read a journal are likely in the past. Perhaps this diminishes the chance that people stumble upon work that sparks their interest by paging through a journal issue, but people are curious and resilient and thus will surely find new ways that I cannot imagine.

\section{NOTES}

1. Ed. note: Rita Felski, “Context Stinks!”, New Literary History, vol. 42, no. 4, 2011, p. 573-591.

2. Ed. note: In 1996, physics professor Alan Sokal submitted an article as a hoax to the journal Social Text, which published it without peer review.

3. Ed. note: In June 2021, Pulitzer-winning journalist and 1619 Project initiator Nikole HannahJones was denied tenure by the University of North Carolina. Although the decision was reversed weeks later after the backlash caused by the decision, Hannah-Jones eventually declined UNC's tenure proposal to join Howard University.

4. Ed. note: Stacey Margolis is J19's co-editor with Elizabeth Duquette.

\section{AUTHORS}

\section{HÉLÈNE QUANQUIN}

Université de Lille, CECILLE

CÉCILE ROUDEAU

Université de Paris, LARCA 